\title{
Comparative transcript profiling of apricot (Prunus armeniaca L.) fruit development and on-tree ripening
}

\author{
George A. Manganaris • Angela Rasori • Daniele Bassi • \\ Filippo Geuna • Angelo Ramina • Pietro Tonutti • \\ Claudio Bonghi
}

Received: 17 March 2010 /Revised: 14 October 2010/Accepted: 19 November 2010 / Published online: 18 January 2011

(C) Springer-Verlag 2011

\begin{abstract}
Considering the high degree of sequence conservation within the Rosaceae family and, in particular, among the Prunus species, we employed the first available peach oligonucleotide microarray ( $\mu$ PEACH 1.0) for studying the transcriptomic profile during apricot (cv. 'Goldrich') fruit development. Apricot fruits were harvested at three distinct developmental stages, corresponding to immature green (6 weeks before fully ripe stage), mature firm ripe (change of peel colour, 1 week before fully ripe stage) and fully ripe, namely $\mathrm{T} 1, \mathrm{~T} 2$ and $\mathrm{T} 3$, respectively. When applied to $\mu$ PEACH1.0, apricot target cDNAs showed significant
\end{abstract}

Communicated by A. Abbott

Electronic supplementary material The online version of this article (doi:10.1007/s11295-010-0360-4) contains supplementary material, which is available to authorized users.

G. A. Manganaris · A. Rasori $\cdot$ A. Ramina $\cdot$ C. Bonghi $(\bowtie)$

Department of Environmental Agronomy and Crop Science,

University of Padova,

Viale dell'Università 16 ,

35020 Legnaro, Padua, Italy

e-mail: claudio.bonghi@unipd.it

\section{G. A. Manganaris}

Department of Agricultural Sciences, Biotechnology and Food

Science, Cyprus University of Technology,

Lemesos 3603, Cyprus

D. Bassi · F. Geuna

Dipartimento di Produzione Vegetale,

Università degli Studi di Milano,

via Celoria 2,

20133 Milan, Italy

P. Tonutti

Scuola Superiore Sant'Anna,

Piazza Martiri della Libertà 33,

56127 Pisa, Italy hybridization with an average of $43 \%$ of spotted probes, validating the use of $\mu$ PEACH1.0 to profile the transcriptome of apricot fruit. Microarray analyses carried out separately on peach (cv. 'Fantasia') and apricot fruit to profile transcriptome changes during fruit development showed that $70 \%$ of genes had the same expression pattern in both species. Such data indicate that the transcriptome is quite similar in apricot and peach fruit and also highlight the presence of species-specific transcript changes. In apricot, 400 and 74 differentially expressed genes were found during the transition from $\mathrm{T} 1$ to $\mathrm{T} 2$ and from $\mathrm{T} 2$ to T3, respectively. Among these, a considerable number of genes encoding IAA protein in action regulators (Aux/IAA) and heat shock proteins (HSPs) were highly up-regulated at early and late ripening, respectively. Intriguingly, the expression profiles of all considered HSPs and some of IAA protein /IAA genes showed different patterns between apricot and peach during the last stages of on-tree fruit development, suggesting the presence of diverse mechanism regulating ripening in these two close phylogenetically related species.

Keywords Rosaceae · Auxin · Transcription factors · Heat shock proteins - Comparative gene expression - Microarray Peach

\section{Introduction}

Ripening of fleshy fruits is characterized by changes in flavour, texture, colour and aroma that are developmentally controlled (Giovannoni 2004). The ripening syndrome has been mainly studied in climacteric fruit and has been shown to involve coordinated metabolic events which, through changes in anatomy, physiology, biochemistry and gene 
expression, lead to the transformation of an unattractive fruit into an appealing one (Giovannoni 2001; 2004). The predominant role of ethylene in the ripening syndrome of climacteric fruits is well documented. More recently, it has been reported that genes involved in IAA protein biosynthesis, transport and signaling are up-regulated in peach mesocarp during ripening, thus strengthening the idea that this hormone is actively involved in the ripening of peaches (Trainotti et al. 2007).

A further elucidation of fruit ripening is feasible with a range of high-throughput transcript profiling approaches, including large-scale expressed sequence tags sequencing, serial analysis of gene expression, massively parallel signature sequencing, cDNA-amplified fragment length polymorphism, differential display RT-PCR and more recently with (oligonucleotide or cDNA) microarrays (reviewed in Bonghi and Trainotti 2006). With the latter technique, it is possible to analyse the expression of thousands of different gene elements in a single experiment (Alba et al. 2004; Soglio et al. 2009). However, such arrays are only available for a few model species, while for less well-documented species other routes are still necessary for informative arrays to be obtained (Kok et al. 2007).

A comparative genomic study, using the available expressed sequence tags (ESTs), between distinct species (grape vs tomato) was conducted and a set of transcription factors induced during ripening in both species was identified (Fei et al. 2004). In addition, microarrays developed for model species have started to be employed as a tool in comparative genomics for gene identification in species where few transcriptomic data are available. Moore et al. (2005) used a tomato microarray (TOM1) to study the transcriptomic ripening profiling in pepper and eggplant, members of the Solanaceae family. The use of a heterologous system (tomato microarray) was found to be a feasible system for analysing differential gene expression in response to enriched $\mathrm{CO}_{2}$ storage conditions in strawberry (Ponce-Valadez et al. 2009). Considering the Prunus genus, the Italian EST consortium has constructed the first available peach microarray, containing 4,806 oligonucleotide probes (70mers) corresponding to a single unigene each (Trainotti et al. 2006). This unigene collection comes from ESTs mainly obtained from libraries of Prunus persica ripening fruit, so it is biased towards this physiological process. Few data regarding the molecular bases of fruit ripening exist for other Prunus species. Apricot is a diploid species $(2 n=8)$ with a genome slightly larger than that of peach, largely uncharacterized, both genetically and biochemically (Geuna et al. 2005). A largescale transcriptomic study of apricot on-tree fruit ripening was carried out using an EST approach by Grimplet et al. (2005) that showed an increase in the transcript levels of genes related to stress conditions and cell wall metabolism.
Considering the high degree of sequence conservation within the Rosaceae family and, in particular, the Prunus genus, we hypothesized that $\mu$ PEACH 1.0 could be a useful tool for studying other Prunus species with limited transcriptome information. Therefore, the current study outlines the potential application of the peach microarray in apricot, a related yet phenotypically distinct species, in order to identify genes differentially expressed during fruit development and ripening. Among these, genes encoding regulators of auxin action (Aux/IAA) and heat shock proteins (HSPs) are present.

\section{Materials and methods}

Plant material

Apricot (Prunus armeniaca L., cv. 'Goldrich') and peach (P. persica L. Batsch, cv. 'Fantasia') fruits were collected from trees grown at the Experimental Station of the Faculty of Agriculture, University of Bologna (Cadriano, Italy). Apricots were sampled at immature green ( 6 weeks before fully ripe stage, named T1), mature firm ripe (1 week before fully ripe stage, start of peel colour change; T2) and fully ripe (commercial harvest; advanced skin pigmentation; T3) stages. At each sampling date, colour and firmness were assessed in 30 fruits. Colour ( $L, a^{*}$, and $b^{*}$ values) was measured using a Minolta colorimeter (model CM2500d) and tissue firmness using an Effegi penetrometer (8-mm probe). The fruit ripening parameters are listed in Supplementary Table S1. Peaches were collected corresponding to the following developmental stages, as described by Trainotti et al. (2007): S1 (first exponential growth), S2 (pit hardening), S3 (mature firm) and S4 (ripe).

The mesocarp tissue of both apricots and peaches was collected at each developmental stage, divided into three sub-lots (ten fruits each), immediately frozen in liquid nitrogen and then stored at $-80^{\circ} \mathrm{C}$ until needed.

RNA extraction and microarray analysis

Frozen mesocarp ( $3 \mathrm{~g}$ ) was ground in liquid nitrogen to a fine powder and total RNA was extracted as described by Bonghi et al. (1998). Fifty micrograms of total RNA was treated with ten units of RQ1 RNase-free DNAse (Promega) and one unit of RNAguard (RNase INHIBITOR) (Amersham) for $30 \mathrm{~min}$ and then purified by phenolchloroform according to the manufacturer's instructions. The concentration of RNA was quantified by measuring the absorbance at $260 \mathrm{~nm}$ and its integrity was checked on agarose gels.

For microarray experiments, the $\mu \mathrm{PEACH} 1.0$ platform (ESTree Consortium 2005; Trainotti et al. 2006) was used. 
Transcriptome analyses of fruit harvested at T1, T2 and T3 for apricot and at S1 and S4 stage for peach were performed following a direct comparison design. Probe synthesis and labelling, hybridization procedure and data analyses were carried out as described by Ziliotto et al. (2008).

Each comparison (T2 vs T1, T3 vs T2 and T3 vs T1 for apricot and S4 vs S1 for peach) was repeated at least four times, one of which was a dye swap. For each gene, at least eight values were generated and subjected to significance analysis for microarrays (SAM) by applying a delta value giving $0 \%$ of false discovery rate. A threshold for the hybridization signal ratio, expressed as $\log _{2}$, was set to be higher than 1 and lower than -1 for selecting up- and downregulated genes, respectively.

Raw and normalized data from all 18 microarrays reported in this study have been deposited in Gene Expression Omnibus (Edgar et al. 2002) public repository and can be accessed at (http://www.ncbi.nlm.nih.gov/geo/ query/acc.cgi?acc $=\mathrm{GSE} 19828)$ using the series accession number GSE19828.

All probes spotted on the $\mu$ PEACH 1.0 were BLASTanalysed against classified proteins from Arabidopsis (release TAIR 8) to categorize them by using the MapMan ontology platform. Based on the best BLAST search results and using a cutoff $e$ value of $10^{-10}$, the peach genes were assigned to BINs/subBINs (i.e. functional classes) according to the most similar Arabidopsis genes. Over- and under-represented BINs were identified by Fisher's exact test using as reference the numbers of clones for each BIN that are present on the $\mu$ PEACH 1.0 as described by Usadel et al. (2006).

\section{Quantification of mRNA via quantitative RT-PCR}

One microgram of total RNA, DNA-free, was reversetranscribed, as described by Sambrook et al. (1989). Transcript accumulation of genes encoding Aux/IAA and HSP was evaluated via quantitative RT-PCR, using the SYBR Green RT-PCR master mix kit (PE Applied Biosystem), as described by Cecchetti et al. (2004). The primer sequences for the selected genes are listed as supplementary material (Table S2).

For each sample (the same used for microarray analyses), three replicates were performed in a final volume of $50 \mu \mathrm{L}$ containing $1 \mu \mathrm{L}$ of single-strand cDNA, 15 pmol of specific primers and $25 \mu \mathrm{L}$ of $2 \mathrm{X}$ SYBR Green PCR Master mix according to the manufacturer's instructions. The internal transcribed spacer of the ribosomal RNA was used as standard gene as reported by Trainotti et al. (2007). The reaction parameters were $10 \mathrm{~min}$ at $95^{\circ} \mathrm{C}$ and then 40 cycles and $1 \mathrm{~min}$ at $72^{\circ} \mathrm{C}$. Each cycle included denaturation at $94^{\circ} \mathrm{C}$ for $30 \mathrm{~s}$, annealing at $64^{\circ} \mathrm{C}$ for $30 \mathrm{~s}$ and extension at $72^{\circ} \mathrm{C}$ for $30 \mathrm{~s}$.
The amount of specific transcripts was calculated following the comparative CT method. Briefly, the amplification plot obtained at the end of the PCR reaction was evaluated and a threshold corresponding to the exponential phase was fixed. The intersection between this threshold and the amplification curve allowed the identification of a point located to the cycle axis. This value was compared to the value of the internal standard and used in the formula $\left(=2^{-\Delta \mathrm{CT}}\right)$ to obtain the expression level.

\section{Results and discussion}

$\mu$ PEACH 1.0 utility for analysing apricot transcriptome

By comparing the position of anchor markers in maps constructed with different Prunus species, it has been demonstrated that the genomes of the diploid Prunus species (including peach and apricot) are essentially co-linear; thus, at the genome level, the Prunus genus can be treated as a single genetic entity (Dirlewanger et al. 2004). This supports the notion that the $\mu$ PEACH 1.0 might be a viable tool for a large transcriptome analysis in apricot. In addition, an in silico comparison at the nucleotide level between the unigene set used to construct the $\mu$ PEACH 1.0 platform and the apricot ESTs from fruit tissues $(15,548$ sequences available at NCBI up to $08 / 01 / 2010$ ) highlighted that more than $80 \%$ of the available sequences showed a significant match in peach (BLAST threshold $1 e^{-10}$ ). Apricot ESTs clustered with 1,725 peach unigenes corresponding to $36 \%$ of the total 4,806 elements on the $\mu$ PEACH 1.0. When apricot-targeted cDNA was applied to $\mu$ PEACH 1.0 , the detectable genes increased up to $43 \%$. This enlarged set may reflect loci shared by apricot and peach fruit and provides a large repertoire of putative markers for comparative studies. All these results clearly show that $\mu$ PEACH 1.0 is a suitable tool for the analysis of apricot fruit gene expression, allowing the identification of genes not characterized in this species at the moment.

\section{Microarray data}

A number of 220 genes appeared to be significant in the SAM analysis by comparing the immature and ripe fruit in apricot (T3 vs T1) and peach (S4 vs S1) (Fig. 1). Among these genes, $71 \%$ showed the same pattern of expression (clusters A and $\mathrm{H}$ ), suggesting that the transcriptome of immature and ripe fruit is quite similar in both species. However, $21 \%$ of the selected genes were differentially expressed only in apricot (clusters $\mathrm{C}$ and $\mathrm{G}$ ) and peach (clusters D and $\mathrm{E}$ ), and $8 \%$ of them displayed an opposite transcription trend with their transcripts being highly accumulated in ripe apricot and immature peach (cluster B) or at a low level in 


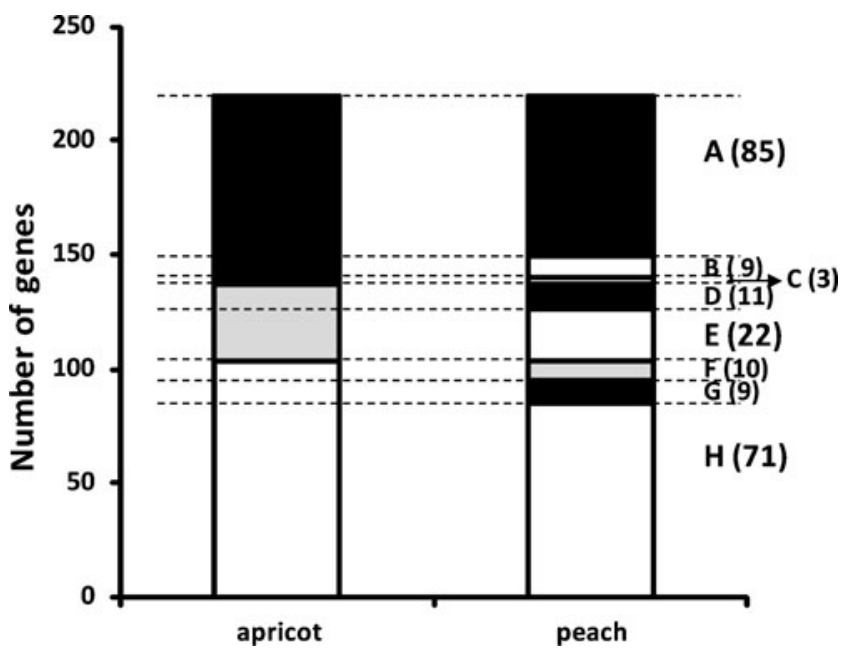

Fig. 1 Clustering of genes, called significant by the significance analysis of microarrays (SAM), on the basis of expression patterns in immature and ripe fruit of apricot and peach. White, grey and black bars indicate up-regulated $\left(\log _{2}\right.$ of expression ratio $\left.>1\right)$, unchanged $\left(\log _{2}\right.$ of expression ratio between 1 and -1$)$ and down-regulated $\left(\log _{2}\right.$ of expression ratio $<-1$ ) genes, respectively, in the comparison ripe vs immature fruit. Cluster $\mathrm{A}$ and $\mathrm{H}$ include genes more expressed in ripe and immature fruit, respectively, shared by apricot and peach. Clusters $\mathrm{C}$ and $\mathrm{G}$ and clusters $\mathrm{D}$ and $\mathrm{E}$ include genes differentially expressed only in apricot or peach, respectively. Clusters B and F group genes with an opposite trend in both species (e.g. cluster B more expressed in ripe apricot and immature peach). Numbers in parenthesis indicate the number of genes for each cluster

immature apricot and ripe peach (cluster F), demonstrating distinctive transcript profiles between peach and apricot (Table S3). Among the most expressed shared genes and in addition to those related to cell wall metabolism and defence, members involved in auxin action (ctg_ 42, 358, 1068 encoding Aux/IAA-like proteins) were present in ripe apricots and peaches, whereas an up-regulation of two ethylene-responsive elements (ctg_750 and 2499) was registered in the immature fruit. These results suggest a crucial role played by these hormones in both apricot and peach maturation and ripening. Ctg_3291 and 3953, showing homology to the protein phosphatase PP2C family members, such as $A B I 1$ and $A B I 2$, resulted as differentially expressed only in apricot. In Arabidopsis, ABI1 is a negative regulator of ABA signaling (Gosti et al. 1999). This is confirmed by the gain in ABA hypersensitivity accompanied by an upregulation of ABA-regulated genes attained through the T-DNA disruption of AtP2C-HA (Leonhardt et al. 2004). In ripe apricot, the expression of PP2C members was higher than in peach, suggesting a lower sensitivity of the latter to ABA. These data might be in some way related to a member (ctg_298) of the gene set with an opposite trend (cluster $\mathrm{G}$ ). The transcripts of this gene, showing homology to the transcription factor ATB2/bZIP11 belonging to the bZIP family, accumulated more abundantly in ripe peach and immature apricot. In AtP2C-HA-defective
Arabidopsis plants, this gene was transcribed at a higher level than in wild type, validating its ABA sensitivity. In fleshy fruit, such as apricot and peach, the ATB2/bZIP11 function and the relationship with ABA are not clear and need to be further elucidated.

Worthy of note is also the ctg 2255 coding for a deduced protein showing a high similarity with TT12, an Arabidopsis proanthocyanidin precursor transporter (Debeaujon et al. 2001), and with MTP77, a tomato putative anthocyanin MATE transporter (Mathews et al. 2003). It has been recently demonstrated that the gene products of orthologs (named AnthoMATE1, 2 and 3) to TT12 and MTP77 are actively involved in the transport of acylated anthocyanin into the vacuole of ripe grape berries (Gomez et al. 2009). In addition, when the MATE transporter gene MTP77 was overexpressed in tomato fruit, a MYB-type transcription factor (ANT1) triggering anthocyanin hyperaccumulation resulted to be up-regulated (Mathews et al. 2003). In apricot and peach, ctg_2255 is differently transcribed as being more expressed in immature apricot fruit and in ripe peach fruit (Table S3), suggesting the presence of a different anthocyanin metabolic pattern and regulation in ripe 'Goldrich' and 'Fantasia' fruits. This result is consistent with a lower accumulation of anthocyanins in 'Goldrich' ripe fruit (Chanine et al. 1999) in comparison with 'Fantasia' (Kubota et al. 2000). Therefore, in order to better clarify the role of the gene corresponding to ctg_2255, it could be interesting to perform specific expression studies in apricot and peach fruit characterized by high levels of anthocyanins in the mesocarp at ripening.

On the basis of these results, $\mu$ PEACH 1.0 was used for profiling the transcriptome of apricot fruit collected at $\mathrm{T} 1$, $\mathrm{T} 2$ and T3 stages. The comparison between T2 vs T1 and T3 vs T2 generated a set of 400 and 74 genes, respectively, differentially expressed. Among these, 232 were upregulated in the first comparison and 44 in the second one, while 168 and 30, respectively, were down-regulated (Table S4). The number of differentially expressed genes indicates that, at the fully ripe stage (T3), only a restricted set was still reactive in terms of transcription regulation. In fact, more than $94 \%$ out of the 400 differentially expressed genes in the T2 vs T1 comparison appeared to be transcriptionally unchanged in the $\mathrm{T} 3$ vs $\mathrm{T} 2$ comparison (Table S4).

Genes differentially expressed at the mature firm stage (T2 vs T1 comparison) and then showing a stable pattern of expression at the fully ripe stage (T3 vs $\mathrm{T} 2$ comparison) were blasted against the Arabidopsis thaliana proteome and then categorized by applying the Mapman ontology vocabulary (Table S4). Among the identified BINs, those over-represented were cell wall (BIN $10, p$ value 0.000262947), lipid (BIN 11.2, $p$ value 0.010409245), hormone (BIN 17, $p$ value 0.002263903 ) and abiotic 
stresses (BIN 20.2, $p$ value 0.004557741) categories, all well known to be ripening-related (Table 1 and supplementary material Table S5). As far as cell wall metabolism is concerned, an over-representation of members of the pectin methylesterase family (BIN 10.8), such as ctg_653 and 1200 among the up-regulated genes and ctg 953 among the down-regulated ones, was observed (Table S3). Concerning lipid metabolism BINs, genes mainly represented were those responsible for fatty acid synthesis (BIN 11.1), such as ctg_521 and 5283 encoding pyruvate dehydrogenases. Within the BIN 17, an enrichment of genes involved in the auxin response (BIN 17.02 including ctg_1741 and 1505 encoding an Aux/IAA-like protein and an auxinresponsive factor, respectively) was observed. In the abiotic stresses subBIN (subBIN 20.2), genes related to heat (ctg_3065 and 3709), cold (ctg_487 and 1160) and drought/salt (ctg_971 and 973) stresses were present. At the fully ripe stage (T3), an over-representation of the HSP family was detected.

Table 1 Over-representation analysis of functional categories carried out by using PageMan. Fisher's exact test was used to test whether significantly more genes in a given category were present, on the basis of their counts in the $\mu$ PEACH 1.0 (Count $\mu$ PEACH 1.0), when T2 and $\mathrm{T} 1$ apricot fruit transcriptomes were compared (Count T2vsT1). In
Considering these data, the results and hypotheses concerning the autonomous role of auxin in peach ripening as reported by Trainotti et al. (2007) and the lack of information about the role of HSPs in fruit ripening, more detailed investigations on auxin-related and HSP gene expression were performed.

\section{Auxin-regulated genes}

The relative expression profiles of fruit-specific Aux/IAA genes obtained by means of real-time qRT-PCR are shown in Fig. 2. High transcript levels were detected for two of them (ctg_42 and 1068), intermediate levels for ctg_57 and 1741 and low levels for ctg_84 and 358. Aux/IAA gene transcripts accumulated at high levels at the mature firm stage (T2) and then a strong decrease, with the exception for ctg_ 84 , was observed at the fully ripe stage (T3).

These results indicated that the expressions of ctgs_57, 358 and 1741 are mainly associated with the mature firm

the table, the overrepresented MapMan functional categories are given by collapsing the non-significant categories. The BIN CODE and corresponding BIN NAME have been assigned as described in "Materials and methods". The complete analysis and its display are provided in Table S5 (supplementary material)

\begin{tabular}{|c|c|c|c|c|}
\hline BIN CODE & BIN NAME & Count T2vsT1 & Count $\mu$ PEACH 1.0 & $p$ value \\
\hline 1.1 & PS.lightreaction & 5 & 12 & 0.004677 \\
\hline 2.2.1.5 & Major CHO metabolism.degradation.sucrose.Susy & 2 & 2 & 0.010409 \\
\hline 3.1 & Minor CHO metabolism.raffinose family & 3 & 4 & 0.003912 \\
\hline 3.01 .02 & Minor CHO metabolism.raffinose family.raffinose synthases & 3 & 4 & 0.003912 \\
\hline 10 & Cell wall & 19 & 79 & 0.000263 \\
\hline 10.8 & Cell wall.pectin*esterases & 6 & 12 & 0.000592 \\
\hline 11.01 .15 & Lipid metabolism.FA synthesis and FA elongation.ACP desaturase & 2 & 2 & 0.010409 \\
\hline 11.01 .31 & Lipid metabolism.FA synthesis and FA elongation.pyruvate DH & 3 & 3 & 0.001059 \\
\hline 11.1 & Lipid metabolism.FA synthesis and FA elongation & 9 & 29 & 0.001722 \\
\hline 11.2 & Lipid metabolism.FA desaturation & 2 & 2 & 0.010409 \\
\hline 13.02 .03 & Amino acid metabolism.degradation.aspartate family & 3 & 5 & 0.00904 \\
\hline 13.2.3.4 & Amino acid metabolism.degradation.aspartate family.methionine & 2 & 2 & 0.010409 \\
\hline 17 & Hormone metabolism & 17 & 79 & 0.002264 \\
\hline 17.02 .03 & Hormone metabolism.auxin.induced-regulated-responsive-activated & 8 & 14 & $1.91 \mathrm{E}-05$ \\
\hline 17.1.1.1.10 & $\begin{array}{l}\text { Hormone metabolism.abscisic acid.synthesis-degradation. } \\
\text { synthesis.9-cis-epoxycarotenoid dioxygenase }\end{array}$ & 2 & 2 & 0.010409 \\
\hline 17.2 & Hormone metabolism.auxin & 9 & 22 & 0.000164 \\
\hline 20.2 & Stress.abiotic & 17 & 82 & 0.004558 \\
\hline 26.18 & Misc.invertase/pectin methylesterase inhibitor family protein & 3 & 4 & 0.003912 \\
\hline 26.21 & $\begin{array}{l}\text { Misc.protease inhibitor/seed storage/lipid transfer protein (LTP) } \\
\text { family protein }\end{array}$ & 4 & 9 & 0.0089 \\
\hline 27.03 .40 & RNA.regulation of transcription.Aux/IAA family & 6 & 7 & 7.03E-06 \\
\hline 29.02 .05 & Protein.synthesis.release & 2 & 2 & 0.010409 \\
\hline 29.2.1.2 & Protein.synthesis.mito/plastid ribosomal protein.mitochondrial & 15 & 70 & 0.004403 \\
\hline 29.5.11.2 & Protein.degradation.ubiquitin.E1 & 2 & 2 & 0.010409 \\
\hline
\end{tabular}



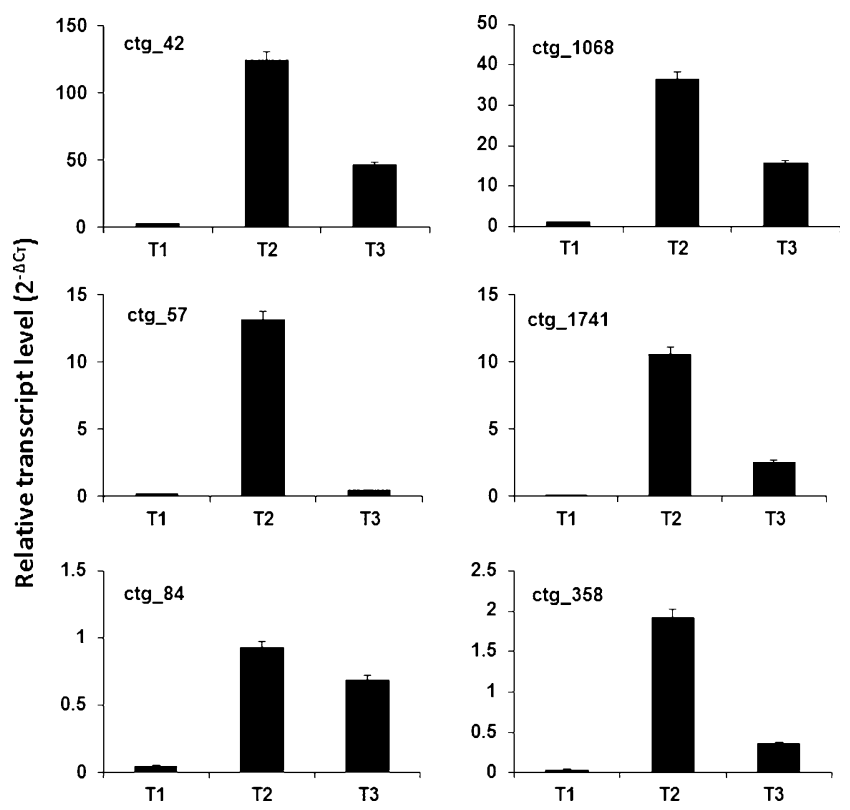

Fig. 2 Relative expression profiles of some auxin genes during apricot fruit development and ripening. Values (means of the normalized expression) have been obtained by means of real-time qRT-PCR. In each panel, the peach contig number is indicated. Bars represent standard deviations from the means. ctg_42: IAA16 protein. [Gossypium hirsutum]; ctg1068: Auxin-induced protein AUX22 [Glycine max]; ctg_57: Auxin-induced protein AUX28 [Glycine max]; ctg 1741: Aux/IAA protein [Populus tremula $x$ Populus tremuloides]; ctg_84: Auxin-induced protein 22D (Indole-3-acetic acid induced protein ARG13) [Phaseolus aureus]; ctg 358: Aux/IAA protein.[Vitis vinifera]. Fruit developmental stages (T1, T2 and T3) are as described in "Materials and methods"

stage and might play a negative role in the late phase of ripening. A negative effect of Aux/IAA genes in the late phase of ripening has been reported for the tomato IAA9 gene (Wang et al. 2005) that shows high homology to the ctg_358. In peach, considering the same set of genes, moving from the onset (namely S4I) to the late phase of ripening (namely S4II), only for ctg_57, 358 and 1741, a slight decrease of transcript accumulation was reported. However, the same genes showed an up-regulation during the transition from the late phase of S3 (namely S3II) to the onset of S4 (namely S4I) (Trainotti et al. 2007). This observation suggests the presence of a partial different mechanism involving the Aux/IAA gene family in the regulation of ripening in apricot and peach fruit. It has been reported that the physiological function of Aux/IAAs is determined by both the pattern of gene expression and the properties of gene products, but gene expression seems to be playing a primary role (Muto et al. 2007). These data, in addition with those reported recently for non-climacteric fruit (Liu et al. 2010), further suggest the need for a physiological reconsideration of auxin action in fruit ripening, independent of ethylene and beyond its wellestablished and documented role in fruit set and growth.
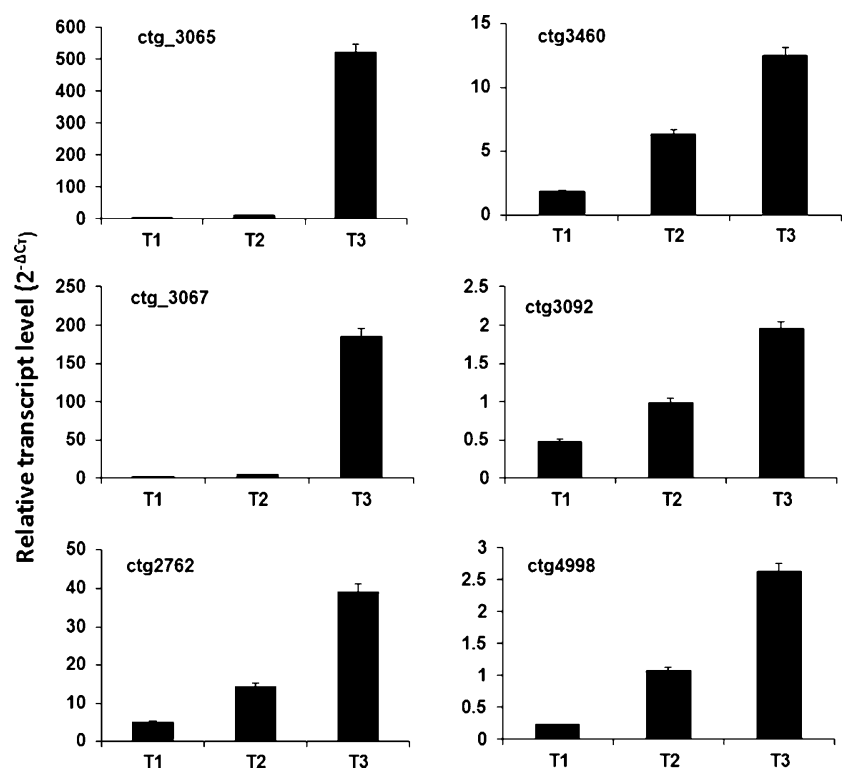

Fig. 3 Relative expression profiles of heat shock protein genes during apricot fruit development and ripening. Values (means of the normalized expression) have been obtained by means of real-time qRT-PCR. In each panel, the peach contig number is indicated. Bars represent standard deviations from the means. ctg 3065: HSP 17.4 [Quercus suber]; ctg_3067: small HSP soybean; ctg_3092: HSP 70 [Arabidopsis thaliana]; ctg_3460: HSP 70 [Cucumis sativus]; ctg_2762: HSP 81-2 [Arabidopsis thaliana]; ctg_4998: putative HSP [Arabidopsis thaliana]. Fruit developmental stages (T1, T2 and T3) are as described in "Materials and methods"
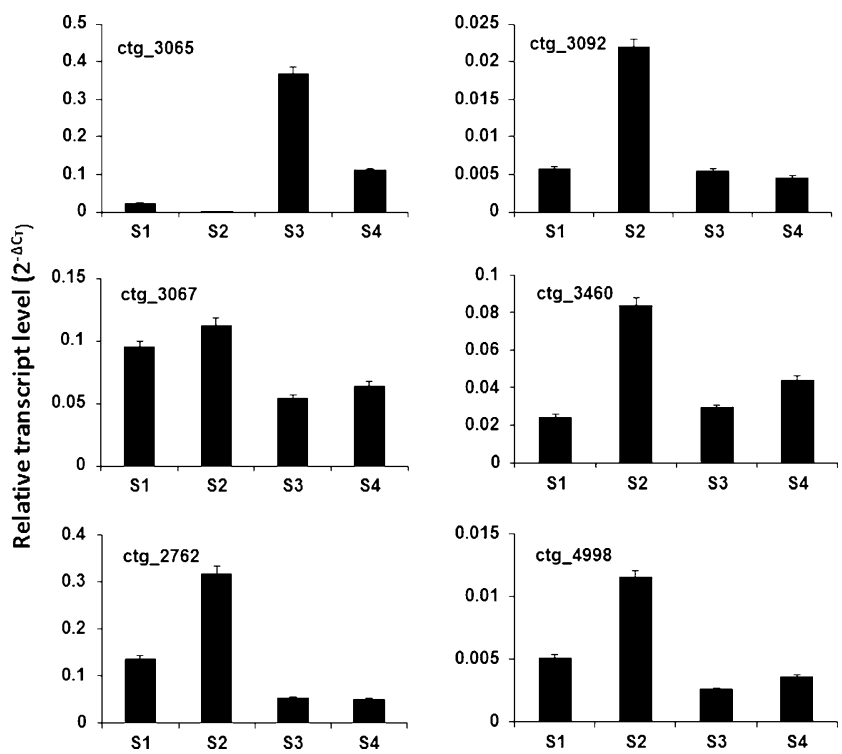

Fig. 4 Relative expression profiles of some heat shock protein genes during peach (cv. 'Fantasia') fruit development and ripening. Values (means of the normalized expression) have been obtained by means of real-time qRT-PCR. In each panel, the peach contig number is indicated. Bars represent standard deviations from the means. For ctg descriptions, see Fig. 3. Fruit developmental stages (S1, S2, S3 and S4) are as described in "Materials and methods" 
HSP genes

An up-regulation of six genes encoding HSPs, particularly during the T2-T3 transition, was observed (Fig. 3). Such data are in accordance with those already reported in apricot (Grimplet et al. 2005) and in other fruit types (Faurobert et al. 2007; Wang et al. 2009).

HSPs are a group of conserved proteins initially described as induced by heat stress but overexpressed also in response to other environmental factors, a variety of physical and chemical stimuli, including oxidative stress (Lindquist 1986; Boston et al. 1996; Wang et al. 2004), and at specific developmental stages such as embryogenesis, microsporogenesis and fruit maturation (Lubaretz and zur Nieden 2002). HSPs are also well known for playing a prominent role in signalling. Proteome analysis carried out during tomato fruit development and ripening showed that most of the HSPs increased throughout fruit development (Faurobert et al. 2007). Their role during ripening is probably linked to the prevention of protein aggregation, facilitation of the renaturation of aggregated proteins during oxidative stress encompassed by the fruit.

HSPs belong to a multigene family, with members playing common or different functional roles. In peach, salicylic acid induced the antioxidant system and the expression of some HSPs, thus alleviating the incidence of chilling injury symptoms occurring after prolonged cold storage (Wang et al. 2006). On the other hand, it has been reported that two HSPs increased in chilling-injured (dry mealy texture) peaches (Obenland et al. 2008). Overexpression of AtHsflb, a heat shock factor gene, enhanced the chilling tolerance in transgenic tomato ( $\mathrm{Li}$ et al. 2003). Neta-Sharir et al. (2005) showed that tomato HSP 21 protects PSII from temperature-dependent oxidative stress and also promotes carotenoid accumulation in developing fruit. Moreover, another tomato small HSP (vis1) is known to play a role in pectin depolymerization during ripening, determining the viscosity attributes of tomato fruit juice (Ramakrishna et al. 2003).

The increasing trend in HSP transcripts that was monitored throughout apricot fruit development and in particular in the T2-T3 transition (Fig. 3) was not detected in peach fruit at the transition from pre-climacteric to climacteric stage as reported by Trainotti et al. (2006) and confirmed by the time-course mRNA accumulation presented in Fig. 4, where a transient transcript accumulation for almost all of the HSP at S2 (corresponding to pit hardening) was observed. Even though the effect on HSP gene expression of the duration of fruit developmental stage cannot be neglected (Ferguson et al. 1998; Wang et al. 2009), this marked different behaviour might be due to the genetic background and some different mechanisms operating in apricot and peach fruit at ripening.

\section{Conclusions}

Genomics tools and approaches are rapidly providing new clues and candidate genes that are expanding the known regulatory circuitry of fruit ripening (Adams-Phillips et al. 2004). Microarrays utilized in a heterologous fashion can be extremely useful tools for gene discovery in species with few available resources, as in the case of stone fruits. The data reported herein make it possible to start building a comparative transcriptional picture of the processes related to fruit development and ripening that may be integrated into current knowledge. This will contribute to the better understanding of evolution and divergence mechanisms of agronomically important fruit crop species belonging to the Prunoideae sub-family. Further research is required to identify genes that are differentially expressed during the development of apricot fruit and their correlation with traits of agronomic interest.

Acknowledgments This paper was produced within the framework of a Marie Curie individual fellowship held by GAM (Grant MEIF-CT2006-038997). PT was in part supported by the DRUPOMICS project (MIPAF). The primers for auxin genes were a gift from Dr. Livio Trainotti., Dept of Biology, University of Padova, Italy. We thank Prof. Barry McGlasson (Centre for Plants and the Environment, University of Western Sydney, Australia) for helpful comments and critical reading of the manuscript.

\section{References}

Adams-Phillips L, Barry C, Giovannoni J (2004) Signal transduction systems regulating fruit ripening. Trends Plant Sci 9:331-338

Alba R, Fei ZJ, Payton P, Liu Y, Moore SL, Debbie P, Cohn J, D'Ascenzo M, Gordon JS, Rose JKC, Martin G, Tanksley SD, Bouzayen M, Jahn MM, Giovannoni J (2004) ESTs, cDNA microarrays, and gene expression profiling: tools for dissecting plant physiology and development. Plant J 39:697-714

Bonghi C, Ferrarese L, Ruperti B, Tonutti P, Ramina A (1998) Endo481 beta-1,4-glucanases are involved in peach fruit growth and 482 ripening, and regulated by ethylene. Physiol Plantarum 102:346-352

Bonghi C, Trainotti L (2006) Genomic tools for a better understanding of the fruit ripening process. Stewart Postharvest Review 2:1-10

Boston RS, Viitanen PV, Vierling E (1996) Molecular chaperones and protein folding in plants. Plant Mol Biol 32:191-222

Cecchetti V, Pomponi M, Altamura MM, Pezzotti M, Marsilio S, D’Angeli S, Tornielli GB, Costantino P, Cardarelli M (2004) Expression of rolB in tobacco flowers affects the coordinated processes of anther dehiscence and style elongation. Plant J 38:512-525

Chanine H, Gouble B, Audergon JM, Souty M, Albagnac G, Jacquemin G, Reich M, Hugues M (1999) Effect of ethylene on certain quality parameters of apricot fruit (Prunus armeniaca, L.) during maturation and postharvest evolution. Acta Hortic 488:577-584

Debeaujon I, Peeters AJM, Leon-Kloosterziel KM, Koornneef M (2001) The TRANSPARENT TESTA 12 gene of Arabidopsis encodes a multidrug secondary transporter-like protein required for flavonoid sequestration in vacuoles of the seed coat endothelium. Plant Cell 13:853-871 
Dirlewanger E, Graziano E, Joobeur T, Garriga-Calderé F, Cosson P, Howad W, Pere A (2004) Comparative mapping and markerassisted selection in Rosaceae fruit crops. Proc Natl Acad Sci USA 101:9891-9896

Edgar R, Domrachev M, Lash AE (2002) Gene expression omnibus: NCBI gene expression and hybridization array data repository. Nucleic Acids Res 30:207-210

ESTree Consortium (2005) Development of an oligo-based microarray ( $\mu$ PEACH1.0) for genomics studies in peach fruit. Acta Hortic 682:263-268

Faurobert M, Mihr C, Bertin N, Pawlowski T, Negroni L, Sommerer $\mathrm{N}$, Causse M (2007) Major proteome variations associated with cherry tomato pericarp development and ripening. Plant Physiol $143: 1327-1346$

Fei ZJ, Tang X, Alba RM, White JA, Ronning CM, Martin GB, Tanksley SD, Giovannoni JJ (2004) Comprehensive EST analysis of tomato and comparative genomics of fruit ripening. Plant $\mathrm{J}$ 40:47-59

Ferguson IB, Snelgar W, Lay-Yee M, Watkins CB, Bowen JH (1998) Expression of heat shock protein genes in apple fruit in the field. Aust J Plan Physiol 25:153-163

Geuna F, Banfi R, Bassi D (2005) Identification and characterization of transcripts differentially expressed during development of apricot (Prunus armeniaca L.) fruit. Tree Genet Gen 1:6978

Giovannoni J (2001) Molecular biology of fruit maturation and ripening. Annu Rev Plant Phys 52:725-749

Giovannoni J (2004) Genetic regulation of fruit development and ripening. Plant Cell 16:S170-S180

Gomez C, Terrier N, Torregrosa L, Vialet S, Fournier-Level A, Verriès C, Souquet J-M, Mazauric J-P, Klein M, Cheynier V, Ageorges A (2009) Grapevine MATE-type proteins act as vacuolar $\mathrm{H}^{+}$dependent acylated anthocyanin transporters. Plant Physiol 150:402-415

Gosti F, Beaudoin N, Serizet C, Webb AAR, Vartanian N, Giraudat J (1999) ABI1 protein phosphatase $2 \mathrm{C}$ is a negative regulator of abscisic acid signaling. Plant Cell 11:1897-1909

Grimplet J, Romieu C, Audergon JM, Marty I, Albagnac G, Lambert P, Bouchet JP, Terrier N (2005) Transcriptomic study of apricot fruit (Prunus armeniaca) ripening among 13006 expressed sequence tags. Physiol Plantarum 125:281-292

Kok EJ, Franssen-van Hal NLW, Winnubst LNW, Kramer EHM, Dijksma WTP, Kuiper HA, Keijer J (2007) Assessment of representational difference analysis (RDA) to construct informative cDNA microarrays for gene expression analysis of species with limited transcriptome information, using red and green tomatoes as a model. J Plant Physiol 164:337349

Kubota N, Mimura H, Shimamura K (2000) Differences in phenolic levels among mature peach and nectarine cultivars and their relation to astringency. J Japan Soc Hort Sci 69:35-39

Leonhardt N, Kwak JM, Robert N, Waner D, Leonhardt G, Schroeder JI (2004) Microarray expression analyses of Arabidopsis guard cells and isolation of a recessive abscisic acid hypersensitive protein phosphatase 2C mutant. Plant Cell 16:596-615

Li HY, Chang CS, Lu LS, Liu CA, Chan MT, Charng YY (2003) Over-expression of Arabidopsis thaliana heat shock factor gene (AtHsflb) enhances chilling tolerance in transgenic tomato. Bot Bul Acad Sin 44:129-140

Lindquist S (1986) The heat-shock response. Annu Rev Biochem 55:1151-1191

Liu D-J, Chen J-Y, Lu W-J (2010) Expression and regulation of the early auxin-responsive Aux/IAA genes during strawberry fruit development. Mol Biol Rep. doi:10.1007/s11033-010-0216-x

Lubaretz O, zur Nieden U (2002) Accumulation of plant small heatstress proteins in storage organs. Planta 215:220-228
Mathews H, Clendennen SK, Caldwell CG, Liu XL, Connors K, Matheis N, Schuster DK, Menasco DJ, Wagoner W, Lightner J, Wagner RD (2003) Activation tagging in tomato identifies a transcriptional regulator of anthocyanin biosynthesis, modification, and transport. Plant Cell 15:1689-1703

Moore S, Payton P, Wright M, Tanksley S, Giovannoni J (2005) Utilization of tomato microarrays for comparative gene expression analysis in the Solanaceae. J Exp Bot 56:2885-2895

Muto H, Watahiki MK, Yamamoto KT (2007) What makes each Aux/IAA gene unique in its gene family, expression pattern or properties of the gene product? Plant Signal Behav $2: 390-392$

Neta-Sharir I, Isaacson T, Lurie S, Weiss D (2005) Dual role for tomato heat shock protein 21: protecting photosystem II from oxidative stress and promoting color changes during fruit maturation. Plant Cell 17:1829-1838

Obenland DM, Vensel WH, Hurkman WJ (2008) Alterations in protein expression associated with the development of mealiness in peaches. J Hortic Sci Biotech 83:85-93

Ponce-Valadez M, Fellman SM, Giovannoni J, Gan SS, Watkins CB (2009) Differential fruit gene expression in two strawberry cultivars in response to elevated $\mathrm{CO}_{2}$ during storage revealed by a heterologous fruit microarray approach. Postharvest Biol Technol 51:131-140

Ramakrishna W, Deng ZP, Ding CK, Handa AK, Ozminkowski RH (2003) A novel small heat shock protein gene, vis1, contributes to pectin depolymerization and juice viscosity in tomato fruit. Plant Physiol 131:725-735

Sambrook J, Fritsch EF, Maniatis T (1989) Molecular cloning: a laboratory manual. Cold Spring Harbor Laboratory, New York

Soglio V, Costa F, Molthoff JW, Weemen-Hedriks WMJ, Schouten HJ, Gianfranceschi L (2009) Transcription analysis of apple fruit development using cDNA microarrays. Tree Genet Genomes 5:685-698

Trainotti L, Bonghi C, Ziliotto F, Zanin D, Rasori A, Casadoro G, Ramina A, Tonutti P (2006) The use of microarray $\mu$ PEACH1.0 to investigate transcriptome changes during transition from pre-climacteric to climacteric phase in peach fruit. Plant Sci 170:606-613

Trainotti L, Tadiello A, Casadoro G (2007) The involvement of auxin in the ripening of climacteric fruits comes of age: the hormone plays a role of its own and has an intense interplay with ethylene in ripening peaches. J Exp Bot 58:3299-3308

Usadel B, Nagel A, Steinhauser D, Gibon Y, BIГasing OE, Redestig H, Sreenivasulu N, Krall L, Hannah MA, Poree F, Fernie AR, Stitt M (2006) PageMan: an interactive ontology tool to generate, display, and annotate overview graphs for profiling experiments. BMC Bioinformatics 7, art. no. 535

Wang W, Vinocur B, Shoseyov O, Altman A (2004) Role of plant heat-shock proteins and molecular chaperones in the abiotic stress response. Trends Plant Sci 9:244-252

Wang H, Jones B, Li ZG, Frasse P, Delalande C, Regad F, Chaabouni S, Latche A, Pech JC, Bouzayen M (2005) The tomato Aux/IAA transcription factor IAA9 is involved in fruit development and leaf morphogenesis. Plant Cell 17:2676-2692

Wang LJ, Chen SJ, Kong WF, Li SH, Archbold DD (2006) Salicylic acid pretreatment alleviates chilling injury and affects the antioxidant system and heat shock proteins of peaches during cold storage. Postharvest Biol Technol 41:244-251

Wang A, Tan D, Tatsuki M, Kasai A, Li T, Saito H, Harada T (2009) Molecular mechanisms of distinct ripening profiles in Fuji apple fruit and its early maturing sports. Postharvest Biol Technol 52:38-43

Ziliotto F, Begheldo M, Rasori A, Bonghi C, Tonutti P (2008) Transcriptome profiling of ripening nectarine (Prunus persica L. Batsch) fruit treated with 1-MCP. J Exp Bot 59:2781-2791 